\title{
Pet-Ct In Patients with Non-Small Cell Lung Cancer: The Use of SUVMax to Evaluate the Primary Tumor and Metastases
}

\author{
Huynh Quang Huy* \\ Radiology Department, Pham Ngoc Thach University of Medicine, Vietnam
}

Received date: November 17, 2018; Published date: December 04, 2018

*Corresponding author: Huynh Quang Huy, Radiology Department, Pham Ngoc Thach University of Medicine, 2 Quang Trung, District 10, Ho Chi Minh city, Vietnam

Abstract

Background: Non-small cell lung cancer (NSCLC) accounts for approximately 80\% of newly diagnosed pulmonary carcinomas. This study investigated the correlation between 18F-fluorodeoxyglucose (FDG) uptake in integrated positron emission tomography with computed tomography (PET-CT) and tumor size, lymph node metastasis, and distant metastasis in patients with NSCLC.

Methods: The records of 318 NSCLC patients (220 male, 98 females; mean age of 60.94 years) were evaluated retrospectively.

Results: Of the cases, 278 were adenocarcinomas, 28 were squamous cell carcinomas, and 12 were large cell carcinomas. When the cases were categorized according to tumor size (group 1: $\leq 3 \mathrm{~cm}$; group 2: $>3$ and $\leq 5 \mathrm{~cm}$; group 3: $>5 \mathrm{~cm}$ ), the maximum standardized uptake value (SUVmax) was found to be significantly lower in groups 1 and 2 , as compared to group 3 ( $\mathrm{p}<0.001)$. With respect to all cases, the tumor SUVmax was not correlated with age, gender, or histological type. Lymph node metastasis was seen in 250 cases: $80.2 \%$ of these were adenocarcinomas, $71.4 \%$ were classified as squamous cell carcinomas, and $58.3 \%$ were large cell carcinomas. Neither lymph node involvement nor distant metastases were correlated with tumor SUVmax, although lymph node size was positively correlated with lymph node SUVmax $(r=0.758 ; p<0.001)$.

Conclusion: SUVmax was significantly associated with tumor size, but not with distant metastases or lymph node involvement. Therefore, SUVmax via PET is not predictive of the presence of metastases.

Keywords: Non-small cell lung cancer; Positron emission tomography; Standardized uptake value; Primary tumor; Lymph node; Distant organ metastasis

\section{Background}

Pulmonary carcinoma is the most commonly diagnosed cancer worldwide (1.61 million cases; $12.7 \%$ of total carcinomas) $[1,2]$ and is the most common cause of cancer death worldwide (1.38 million deaths; $18.2 \%$ of total cancer deaths) [3]. Nonsmall cell lung cancer (NSCLC) accounts for approximately $80 \%$ of new pulmonary carcinoma diagnoses, and consists of various histological subtypes, including adenocarcinoma (ACC), squamous cell carcinoma (SCC), large cell carcinoma (LCC), and mixed histology [4]. Recently, the uptake of 18F-fluorodeoxyglucose (FDG) as determined by integrated positron emission tomography with computed tomography (PET-CT) has become a widely used non-invasive diagnostic test [5]. 18F-FDG PET-CT measures the standardized uptake value (SUV) of a pulmonary mass, which quantifies the glucose avidity of the tumor [6]. FDG PET-CT has been shown to be useful for evaluating an indeterminate pulmonary nodule, staging lymph nodes, and evaluating local nodal and distant metastases. FDG uptake correlates with the proliferative activity of a tumor and is an independent prognostic factor in patients with lung cancer [7-10]. The objective of the present study was to assess whether SUVmax in PET-CT correlates with tumor size, lymph node metastasis, distant metastasis, and tumor histopathological type in NSCLC patients.

\section{Patients and Methods}

\section{Study Population}

The records of 318 patients newly diagnosed with NSCLC in the Nuclear Medicine and Oncology Center of Bach Mai Hospital between November 2015 and October 2018 were evaluated retrospectively. The subjects were examined by FDG PET-CT and histological diagnosis of masses. A total of 220 males and 98 females were included in the study, with a mean age of $60.9 \pm 9.1$ years (range: $28-88$ years). Pathologically, there were 278 adenocarcinomas (ACC), 28 squamous cell carcinomas (SCC), and 12 large cell carcinomas (LCC).

\section{FGD PET-CT Imaging}

All patients underwent diagnostic and/or staging with FDG PET-CT prior to biopsy or therapy. Patients were asked to fast 


\section{Current Trends in Clinical \& Medical Imaging}

at least 6hours before the FDG PET-CT scan. All patients had a glucose level below $180 \mathrm{mg} / \mathrm{dl}$ and were injected intravenously with $0.15-0.20 \mathrm{mCi} / \mathrm{kg}$ (7-12 mCi) FDG. At 45-60 min after the injection, data were acquired from the vertex to the upper thigh. Immediately after CT, a PET scan (PET/CT Biograph True Point, Siemens, Germany) was performed for approximately $25 \mathrm{~min}$, with 7 to 8 bed positions and $3 \mathrm{~min} /$ position. PET images were reconstructed iteratively with CT data for attenuation correction, using an inline integrated Siemens E.Soft Workstation system (Germany). PET-CT fusion images in transaxial, sagittal, and coronal planes were evaluated visually, and the SUVmax of lesions was obtained from transaxial images.

\section{Statistical Evaluation}

Statistical analysis was performed using SPSS software (version 12.0). Values were expressed as mean \pm standard deviation (SD). The differences of tumor SUVmax in 2 independent groups were compared using Mann Whitney $U$ test and in more than two independent groups were compared using Kruskal-Wallis test. Spearman's correlations were computed between tumor SUVmax and tumor diameter, mediastinal lymph node diameter, and lymph node SUVmax. Independent sample t-test was used to determine the significance of the difference in tumor SUVmax, according to the presence of lymph node or distant metastases. Statistical significance was set at the level of $\mathrm{p}<0.05$.

\section{Results}

The characteristics and SUVmax of the 318 NSCLC cases are summarized in Table 1 . When the cases were divided into three groups based on tumor size (group 1: $\leq 3 \mathrm{~cm}$; group 2: $>3 \mathrm{~cm}$ and $\leq 5 \mathrm{~cm}$; group 3: $>5 \mathrm{~cm}$ ), tumor SUVmax was found to differ significantly among all groups $(p<0,001)$. With respect to all the cases, tumor SUVmax was significantly correlated with histological type (adenocarcinoma vs squamous cell carcinoma and large cell carcinomas), but not with age or gender. A significant relationship was found between tumor SUVmax and tumor size $(r=0.541$; $\mathrm{p}<0.001$ ) in Figure 1.

Table 1: Characteristics and SUVmax of the NSCLC cases.

\begin{tabular}{|c|c|c|c|}
\hline & n (\%) & $\begin{array}{c}\text { SUV } \\
(\text { Mean } \pm \text { SD) }\end{array}$ & $P$ value \\
\hline \multicolumn{4}{|l|}{ Sex } \\
\hline Male & $220(69.2)$ & $11.36 \pm 5.83$ & \multirow{2}{*}{0.17} \\
\hline Female & $98(30.8 \%)$ & $10.02 \pm 4.25$ & \\
\hline \multicolumn{4}{|l|}{ Histology } \\
\hline Adenocarcinoma & $278(87.4 \%)$ & $10.75 \pm 5.30$ & \multirow{3}{*}{$0.021^{*}$} \\
\hline $\begin{array}{c}\text { Squamous cell Car- } \\
\text { cinoma }\end{array}$ & $28(8.8 \%)$ & $12.37 \pm 6.81$ & \\
\hline Large cell Carcinomas & $12(3.8 \%)$ & $12.17 \pm 4.22$ & \\
\hline \multicolumn{4}{|l|}{ Tumor size } \\
\hline$\leq 3 \mathrm{~cm}$ & $88(22.7 \%)$ & $7.31 \pm 2.97$ & \multirow{3}{*}{$<0.001$} \\
\hline$>3 \leq 5 \mathrm{~cm}$ & $114(35.8 \%)$ & $10.62 \pm 4.19$ & \\
\hline$>5 \mathrm{~cm}$ & $116(36.5 \%)$ & $14.03 \pm 6.11$ & \\
\hline \multicolumn{4}{|l|}{$\begin{array}{l}\text { Lymph Node Metas- } \\
\text { tasis }\end{array}$} \\
\hline N0-N1 & $86(27.0 \%)$ & $9.65 \pm 5.39$ & \multirow{2}{*}{0.001} \\
\hline N2-N3 & $232(73.0 \%)$ & $11.43 \pm 5.37$ & \\
\hline \multicolumn{4}{|l|}{ Distant Metastasis } \\
\hline M0 & $144(45.3 \%)$ & $10.83 \pm 5.15$ & \multirow{4}{*}{0.889} \\
\hline M1 & $28(8.8 \%)$ & $11.53 \pm 6.22$ & \\
\hline M2 & $61(19.2 \%)$ & $10.83 \pm 6.05$ & \\
\hline M3 & $85(26.7 \%)$ & $11.04 \pm 5.20$ & \\
\hline
\end{tabular}

*Mann Whitney U test for 2 independent groups: 278 adenocarcinomas vs 40 others (Squamous cell carcinomas + Large cell carcinomas).

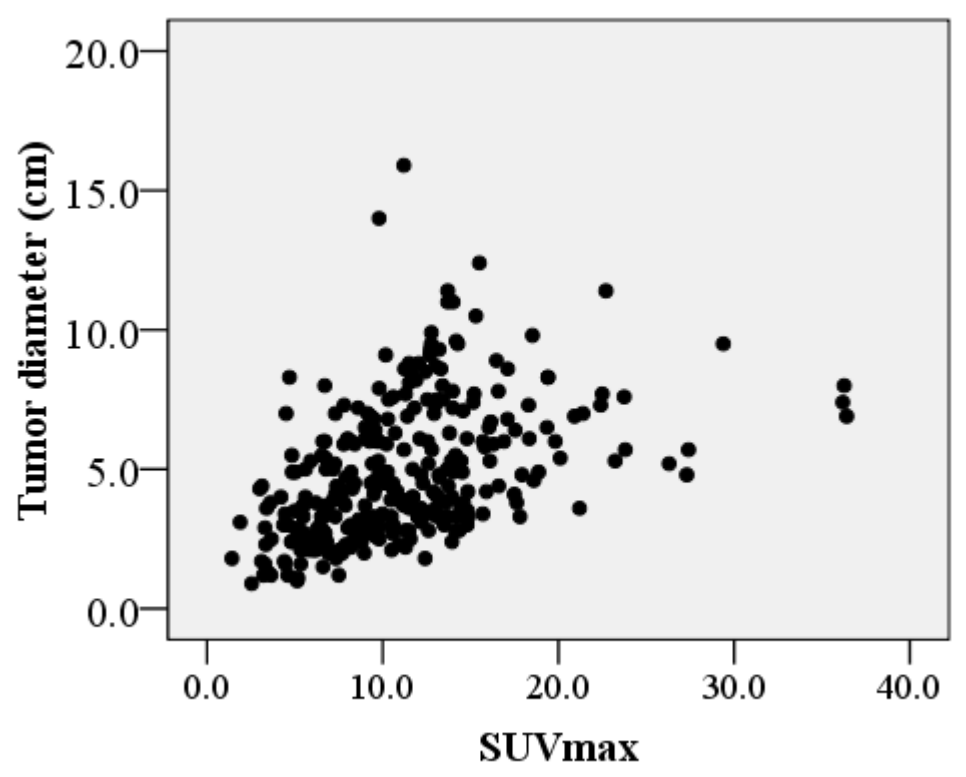

Figure 1: Relationship between tumor SUVmax and tumor size $(r=0.541 ; p<0.001)$. 


\section{Current Trends in Clinical \& Medical Imaging}
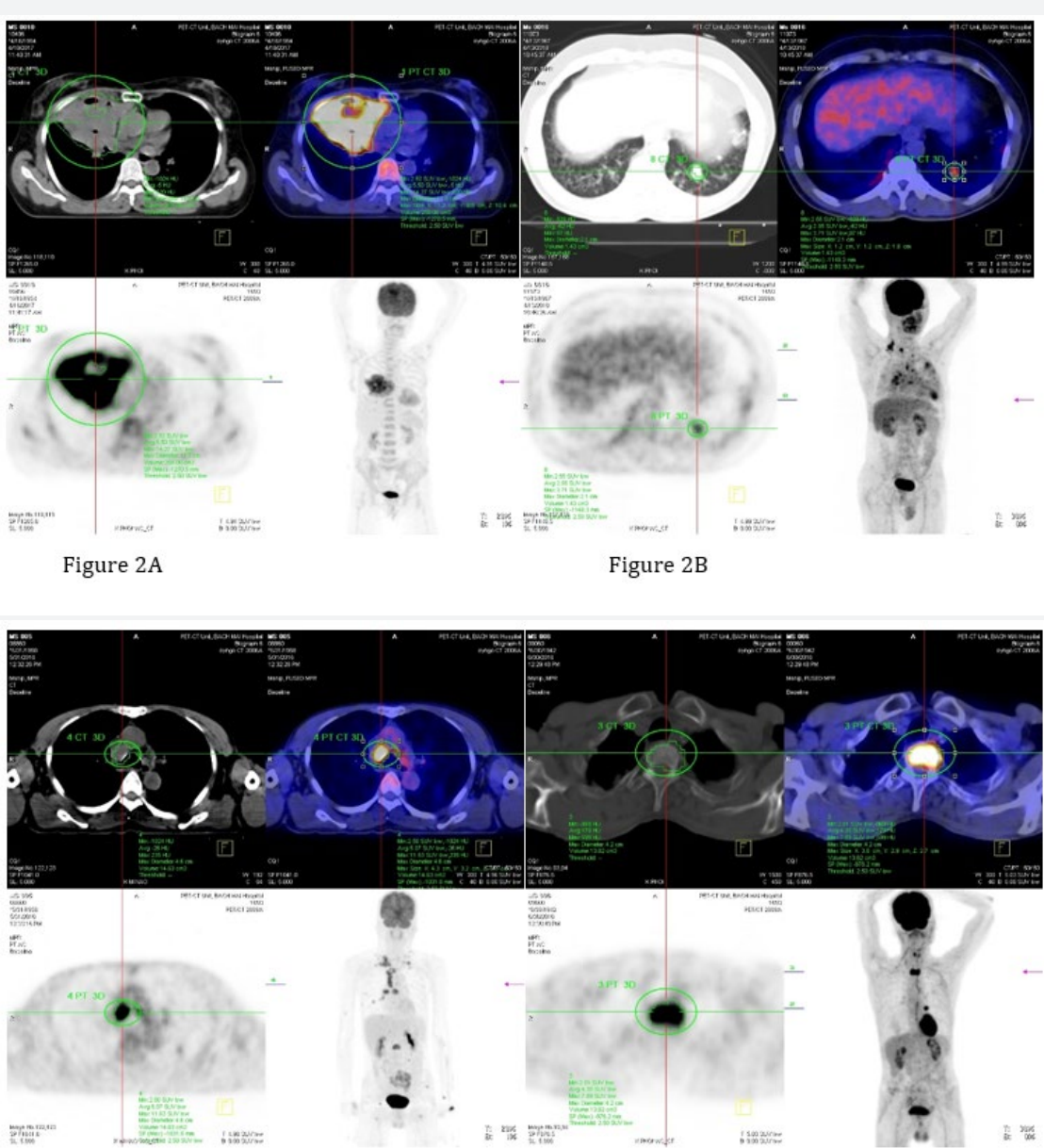

Figure 2c

Figure 2D

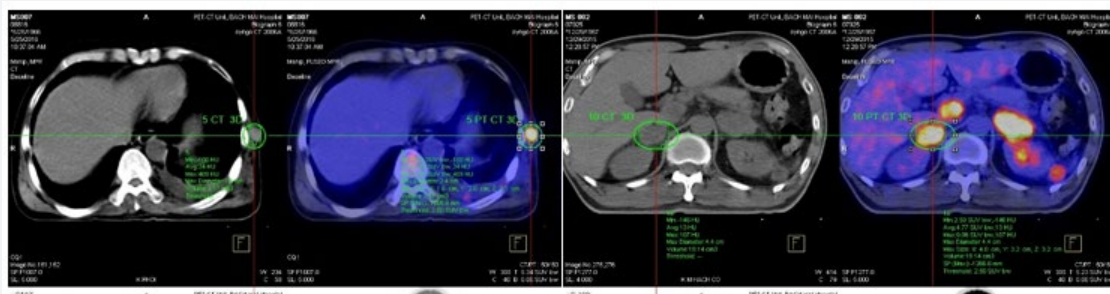

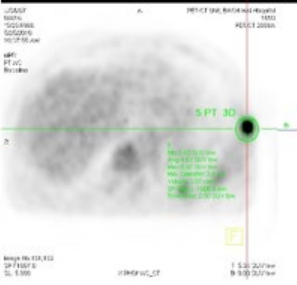

Figure 2E

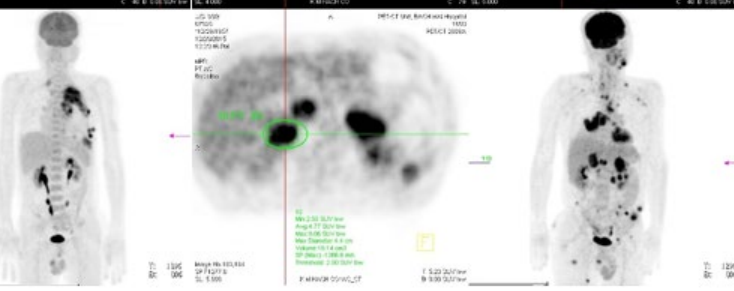

Figure 2F

Figure 2: PET-CT images of patients with NSCLC.

Among the 318 cases, lymph node metastasis were seen in 250 cases $(78.6 \%)$. Lymph node metastases were present in $80.2 \%$ $(223 / 278)$ of adenocarcinomas, $71.4 \%(20 / 28)$ of squamous cell carcinomas, and 58.3\% (7/12) of large cell carcinomas. When cases were divided into 2 groups according to lymph node involvement, there was significantly difference in tumor SUVmax among the groups (Table 1). And, lymph node size was positively correlated with lymph node SUVmax $(r=0.758, \mathrm{p}<0.001)$. Tumor SUVmax did not differ significantly according to the presence of distant metastases. Primary tumor (Figure 2A - tumor diameter $11.9 \mathrm{~cm}$; SUVmax 14.27). Lung metastasis (Figure 2B - tumor diameter $2.1 \mathrm{~cm}$; SUVmax 3.71). Mediastinal metastasis (Figure 2C - tumor diameter $4.6 \mathrm{~cm}$; SUVmax 11.63). Vertebral metastasis (Figure 2D - tumor diameter $4.2 \mathrm{~cm}$; SUVmax 7.89). Thoracic wall 


\section{Current Trends in Clinical \& Medical Imaging}

muscle metastasis (Figure 2E - tumor diameter $2.4 \mathrm{~cm}$; SUVmax 8.97). Adrenal gland metastasis (Figure $2 \mathrm{~F}$ - tumor diameter 4.4 cm; SUVmax 9.06)

\section{Discussion}

Although CT or magnetic resonance imaging (MRI) provides precise anatomical and morphological information, the role of FDG PET-CT has increased for diagnosis and staging of lung cancer. Recently, FDG uptake has been reported to be a prognostic factor in patients with lung cancer [8]. Patz et al. [11] demonstrated that patients with positive FDG PET-CT results in treated lung cancer had a significantly worse prognosis than those with negative results. Therefore, we examined whether SUVmax correlates with tumor size, lymph node and distant metastases in patients with NSCLC. Tumor size, but not lymph node or distant metastases, was related to tumor SUVmax. Doom et al. [12] also reported a strong significant association between tumor size and SUVmax in patients with NSCLC. Another study in patients with stage I NSCLC showed a significant association between the primary tumor, SUVmax and tumor size, with tumors $\leq 3 \mathrm{~cm}$ having a significantly lower SUV than tumors $>3 \mathrm{~cm}$ [13].

Aquino et al. [14] reported a significant difference in FDG uptake between the well-differentiated adenocarcinoma subtype bronchioloalveolar carcinoma (BAC) and non-BAC adenocarcinomas, including well-differentiated non-BAC tumors. Adenocarcinomas with mixed features that included BAC had a peak SUV $(1.5 \pm 0.2)$ lower than that of all other non-BAC adenocarcinomas (SUV: $3 \pm 1.5$ ), which included one poor tumor, three moderate tumors, and one well-differentiated tumor [14]. Vesselle et al. [6] showed that the uptake by large cell carcinomas was greater than that by adenocarcinomas, and was not significantly different from uptake by squamous cell carcinomas. However, we observed no difference in SUVmax among histological types. Our data are in concordance with previous studies that have documented lower uptake by adenocarcinomas compared with squamous cell carcinomas, and lower uptake by BAC adenocarcinomas compared with non-BAC adenocarcinomas.

FDG PET-CT is already an indispensable modality for evaluating lymph node and distant metastases. Many reports have suggested that FDG PET-CT is superior to CT in terms of accuracy of N-staging for lung cancer. Therefore, FDG PET-CT is now regarded as the most accurate imaging modality for $\mathrm{N}$-staging of lung cancer. However, a significant number of false-negative and false-positive findings of lung cancer, including $\mathrm{N}$-staging on FDG-PET-CT, have been reported. Nambu et al. [15] demonstrated that the likelihood of lymph node metastasis increased with an increase in SUVmax of the primary tumor. For primary lung cancer with a SUVmax greater than 12, the probability of lymph node metastasis was high, reaching $70 \%$, irrespective of the degree of FDG accumulation in the lymph node stations. Thus, the authors concluded that their findings allow a more sensitive prediction of the presence of lymph node metastases, including the microscopic ones that cannot be detected by direct evaluation of lymph node stations. Consistent with these results, Higashi et al. [16] documented in a multicenter study that the incidence of lymphatic vessel invasion and lymph node metastasis in NSCLC were associated with 18 F-FDG uptake. Thus, 18F FDG uptake by a primary tumor is a strong predictor of lymphatic vessel invasion and lymph node metastasis.

In the present study, although tumor SUVmax was higher in patients with lymph node metastases than in those without, the difference did not reach statistical significance. Ozgül et al. [17] observed that the frequency of lymph node metastasis was higher in adenocarcinomas (80.2\%) than in squamous cell carcinomas (71.4\%), suggesting that pathological subtype may be a significant factor associated with lymph node metastasis. In contrast, a previous study showed no difference in the frequency of lymph node metastasis between the two pathological subtypes [15].

Based on univariate analysis, Jeong et al. [18] concluded that the metastasis detected by PET imaging, which can affect staging by aiding in the discovery of metastasis to contralateral lymph nodes or distant organs, was an insignificant factor, and that metastatic findings on PET had weak discriminative power. According to Cerfolio et al. [19], FDG-PET-CT does not replace the need for tissue biopsies for staging N1 or N2 lymph nodes, or metastatic lesions, as false positives and false negatives were observed in all stations in their study. However, FDG-PET-CT resulted in better patient selection before pulmonary resection. FDG-PET was also helpful in targeting areas for biopsy and identifying unsuspected N2 and M1 disease [19]. In the present study, tumor SUVmax was not significantly correlated with distant metastases. This may be attributable to the finding of increased 18 F-FDG uptakes by subclinical inflammatory lesions as well as by malignant tumors.

\section{Conclusion}

SUVmax was associated with tumor size, but not with distant metastases or lymph node involvement. Thus, SUVmax determined by FDG-PET-CT is not predictive of the presence of metastases. Moreover, SUVmax was significantly related to histology of tumor. Larger prospective and randomized analyses may potentially reveal more significant relationships.

\section{References}

1. Alberg AJ, Brock MV, Ford JG, Samet JM, Spivack SD (2013) Epidemiology of lung cancer: Diagnosis and management of lung cancer, $3^{\text {rd }}$ ed: American College of Chest Physicians evidence-based clinical practice guidelines. Chest 143(5 Suppl): e1S-e29S.

2. Dela Cruz CS, LT Tanoue, RA Matthay (2011) Lung cancer: epidemiology, etiology, and prevention. Clin Chest Med 32(4): 605-644.

3. Bray F, Ferlay J, Soerjomataram I, Siegel RL, Torre LA, et al. (2018) Global cancer statistics 2018: GLOBOCAN estimates of incidence and mortality worldwide for 36 cancers in 185 countries. CA Cancer J Clin 68(6): 394-424.

4. Vesselle H, Salskov A, Turcotte E, Wiens L, Schmidt R, et al. (2008) Relationship between non-small cell lung cancer FDG uptake at PET, tumor histology, and Ki-67 proliferation index. J Thorac Oncol 3(9): 971-978.

5. De Wever, Stroobants S, Coolen J, Verschakelen JA (2009) Integrated PET/CT in the staging of nonsmall cell lung cancer: technical aspects and clinical integration. Eur Respir J 33(1): 201-212. 


\section{Current Trends in Clinical \& Medical Imaging}

6. Kinahan PE, JW Fletcher (2010) Positron emission tomographycomputed tomography standardized uptake values in clinical practice and assessing response to therapy. Semin Ultrasound CT MR 31(6): 496-505.

7. Cerfolio RJ, Bryant AS, Ohja B, Bartolucci AA (2005) The maximum standardized uptake values on positron emission tomography of a nonsmall cell lung cancer predict stage, recurrence, and survival. J Thorac Cardiovasc Surg 130(1): 151-159.

8. Dhital K, Saunders CA, Seed PT, O’Doherty MJ, Dussek J, et al. (2000) [(18) F]Fluorodeoxyglucose positron emission tomography and its prognostic value in lung cancer. Eur J Cardiothorac Surg 18(4): 425428

9. Hanin FX, Lonneux M, Cornet J, Noirhomme P, Coulon C, et al. (2008) Prognostic value of FDG uptake in early stage non-small cell lung cancer. Eur J Cardiothorac Surg 33(5): 819-823.

10. Al-Sarraf N, Gately K, Lucey J, Aziz R, Doddakula K, et al. (2008) Clinical implication and prognostic significance of standardised uptake value of primary non-small cell lung cancer on positron emission tomography: analysis of 176 cases. Eur J Cardiothorac Surg 34(4): 892-897.

11. Patz EF Jr, J Connolly, J Herndon (2000) Prognostic value of thoracic FDG PET imaging after treatment for non-small cell lung cancer. AJR Am J Roentgenol 174(3): 769-774.

12. Dooms C, van Baardwijk A, Verbeken E, van Suylen RJ, Stroobants S, et al. (2009) Association between 18F-fluoro-2-deoxy-D-glucose uptake values and tumor vitality: prognostic value of positron emission tomography in early-stage non-small cell lung cancer. J Thorac Oncol 4(7): 822-828.
13. Um SW, Kim H, Koh WJ, Suh GY, Chung MP, et al. (2009) Prognostic value of 18F-FDG uptake on positron emission tomography in patients with pathologic stage I non-small cell lung cancer. J Thorac Oncol, 4(11): 1331-1336.

14. Aquino SL, Halpern EF, Kuester LB, Fischman AJ (2007) FDG-PET and CT features of non-small cell lung cancer based on tumor type. Int J Mol Med 19(3): 495-499.

15. Nambu A, Kato S, Sato Y, Okuwaki H, Nishikawa K, et al. (2009) Relationship between maximum standardized uptake value (SUVmax) of lung cancer and lymph node metastasis on FDG-PET. Ann Nucl Med 23(3): 269-275.

16. Higashi K, Ito K, Hiramatsu Y, Ishikawa T, Sakuma T, Matsunari I, et al. (2005) 18F-FDG uptake by primary tumor as a predictor of intratumoral lymphatic vessel invasion and lymph node involvement in non-small cell lung cancer: analysis of a multicenter study. J Nucl Med 46(2): 267-273.

17. Ozgül MA, Kirkil G, Seyhan EC, Cetinkaya E, Ozgül G, et al. (2013) The maximum standardized FDG uptake on PET-CT in patients with nonsmall cell lung cancer. Multidiscip Respir Med 8(1): 69.

18. Jeong HJ, Min JJ, Park JM, Chung JK, Kim BT, et al. (2002) Determination of the prognostic value of [(18)F] fluorodeoxyglucose uptake by using positron emission tomography in patients with non-small cell lung cancer. Nucl Med Commun 23(9): 865-870.

19. Cerfolio RJ, Ojha B, Bryant AS, Bass CS, Bartalucci AA, et al. (2003) The role of FDG-PET scan in staging patients with nonsmall cell carcinoma. Ann Thorac Surg 76(3): 861-866.

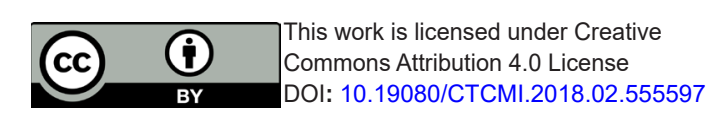

\section{Your next submission with Juniper Publishers will reach you the below assets}

- Quality Editorial service

- Swift Peer Review

- Reprints availability

- E-prints Service

- Manuscript Podcast for convenient understanding

- Global attainment for your research

- Manuscript accessibility in different formats ( Pdf, E-pub, Full Text, Audio)

- Unceasing customer service

Track the below URL for one-step submission https://juniperpublishers.com/online-submission.php 